\title{
Riverside Market Project, San Isidro de Heredia, Costa
}

\section{Rica}

\author{
Julio Jiménez
}

JUSA-Total Project Care, Architect/Engineer, Costa Rica

\begin{abstract}
During 2011 a client came seeking assistance for the development of a roadside property located on the main highway to the Caribbean Coast from Costa Rica's capital San José; he had in mind a barbecue restaurant for truckers and road users, but was challenged to ponder on pursuing a truly sustainable and inclusive approach for his project. A living and evolving micro-urban system inspired in permaculture was proposed. After the initial conversations, the owner went on to study sustainable production practices, bio-intensive agriculture, wood construction and related topics. He came back on 2013 and the first phase was finally built in 2015. It all was to start as a small roadside café, with the eventual establishment of an organic marketplace. Significant portions of old walls and floors remaining on site, as fragments of a formerly burned down building, were salvaged/recycled and utilized in combination with new light wood structures, minimally touching the ground yet maximizing space quality and use. The small cafe quickly turned into a lively and successful brick-oven pizza place and gastro-pub with current plans to expand into the diversified organic marketplace once imagined. Key sustainable building features include the salvaging of existing structures and floors, the use of reforestation wood (teak, melina) processed on site, and the implementation of passive tropical design strategies. The project has its own organic orchard and composting systems and priority is given to locally sourced produce and products. Electrical energy expenditure is minimized by traditional wood cooking methods. The venue has positively influenced and contributed to the local community and the sustainable/organic culture of our small green country. It all combines together to create a business model based on sustenance, learning and information exchange, adding up to much more than the sum of its parts.
\end{abstract}

Key words: Low carbon, adaptive, passive tropical, micro-urbanism.

\section{Introduction}

Over the course of the year 2011, the author of this paper, Julio Jiménez as architect/engineer, met with the land owner in order to start design work on a project located in San Isidro de Heredia, Costa Rica. Since September 2009, Julio had been pursuing postgraduate studies in sustainability at the CAT (Center for Alternative Technologies), focusing mainly on passive tropical design for non-developed regions, adaptive principles, permaculture and holistic approaches, all in order to come up with proposals for an architecture of the present time in our home country, Costa Rica.

Conversations started on the original idea of building a roadside restaurant, but the scope and

Corresponding author: Julio Jiménez, B.Sc. civil engineering, MS engineering, architecte DPLG; research field: passive and low carbon design. vision of the project quickly turned into the dream of an evolving and sustainable micro-urban market conceptually based more on permaculture principles adapted to our local realities, rather than on the more prevalent eco-efficient practices [1-3]. Taking it at heart, Dan went on to prepare himself for the challenge, studying on his own the principles of sustainable development, bio-intensive agriculture, sustainable wood processing and construction, among other related topics of interest to the project. The design process finally started after more than a year of further preparation.

From the onset, the austere and simple building newly raised was like a magnet for sensitive persons looking for alternative places for leisure and enjoyment. Further on, it has attracted people from all standards, classes, trades, cultures and ages, unfolding since its beginning as an inclusive venture for all 
(Fig. 1). Being completely self-financed, the business is now ready to expand, incorporating new market elements that will take it one step further into the lively micro-urban system once envisioned.

We are convinced that what has made Riverside Market a successful venture both from a business and sustainable design standpoint has been focusing on the root of a vision carried out honestly and attentively respecting the simple but key principles upon which it rests [4-6].

\section{Implemented Vision}

The vision established from the beginning was that of a lively, permanent food and retail space for commerce of sustainable products, focusing on artesian, healthy, local products both for taking out and in-place consumption. The place would act as a showcase for both traditional and innovative food preparation approaches, arts and crafts as well as live music. The finishing of the spaces would be simple, un-pretentious, yet comfortable, for people to enjoy their time while chatting, shopping, eating and relaxing with friends and family in an informal, market-style environment (Fig. 2). The whole design and construction process was to be performed bearing in mind the patient and constant unfolding of events on a step-by-step basis.

A very important feature of the vision for the place included the establishment of an open and free setting for the exchange of information regarding the production, the practices, the care, all producing an experience for the people, as important as the inherent commerce of goods.

The feedback generated by this information exchange dynamics, back into the project, contributed to creating a living organization requiring continuous evaluation, analysis and modifications/improvements over time. As a result, the vision of the project transpires within the physical setting of the place and its values are transmitted through experience, rather than explicitly expressed in written or verbal terms, therefore generating interest out of the emotional response of the users to the lived experience within the space.

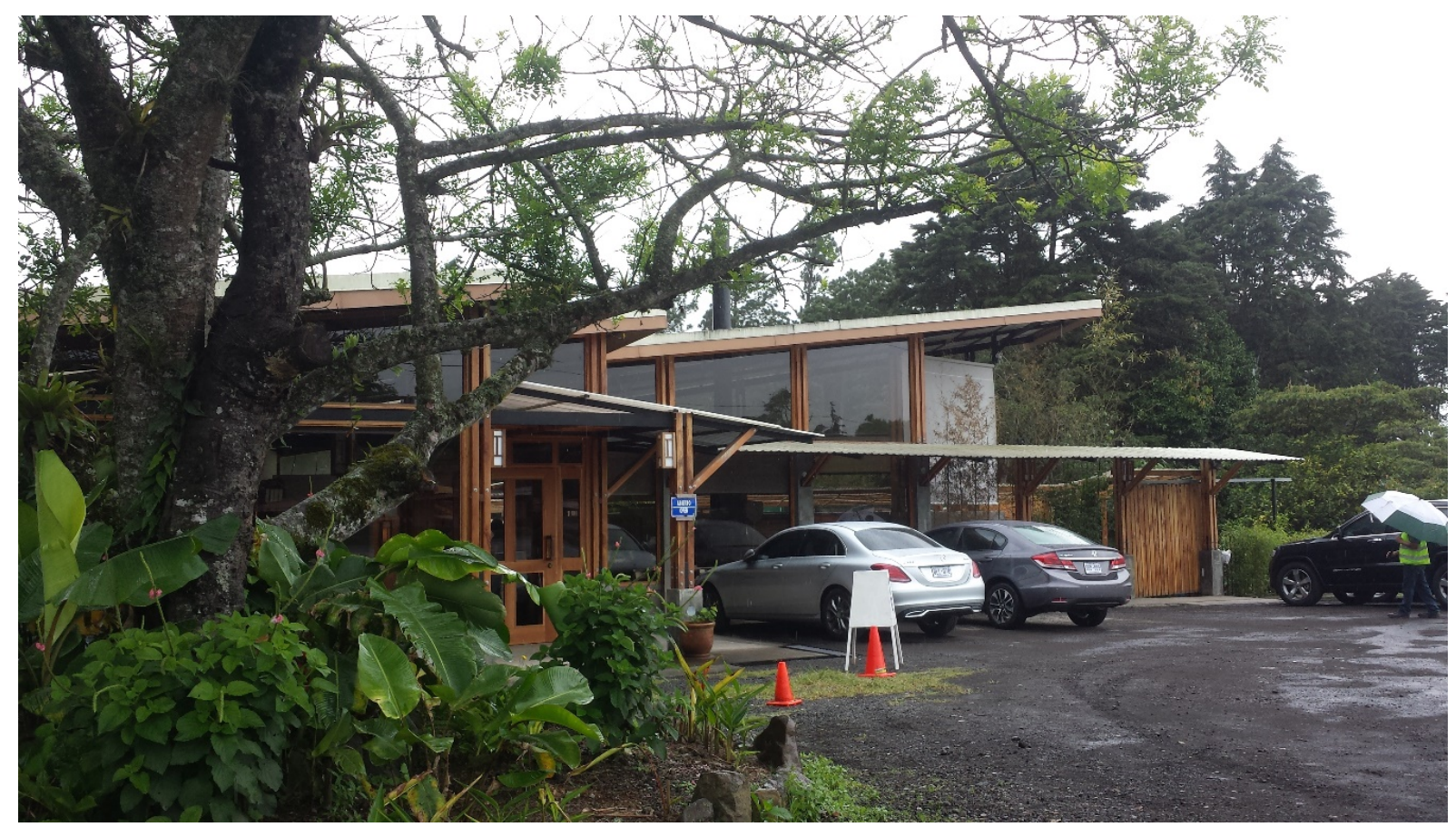

Fig. 1 Riverside Market first phase: roadside café/restaurant. 


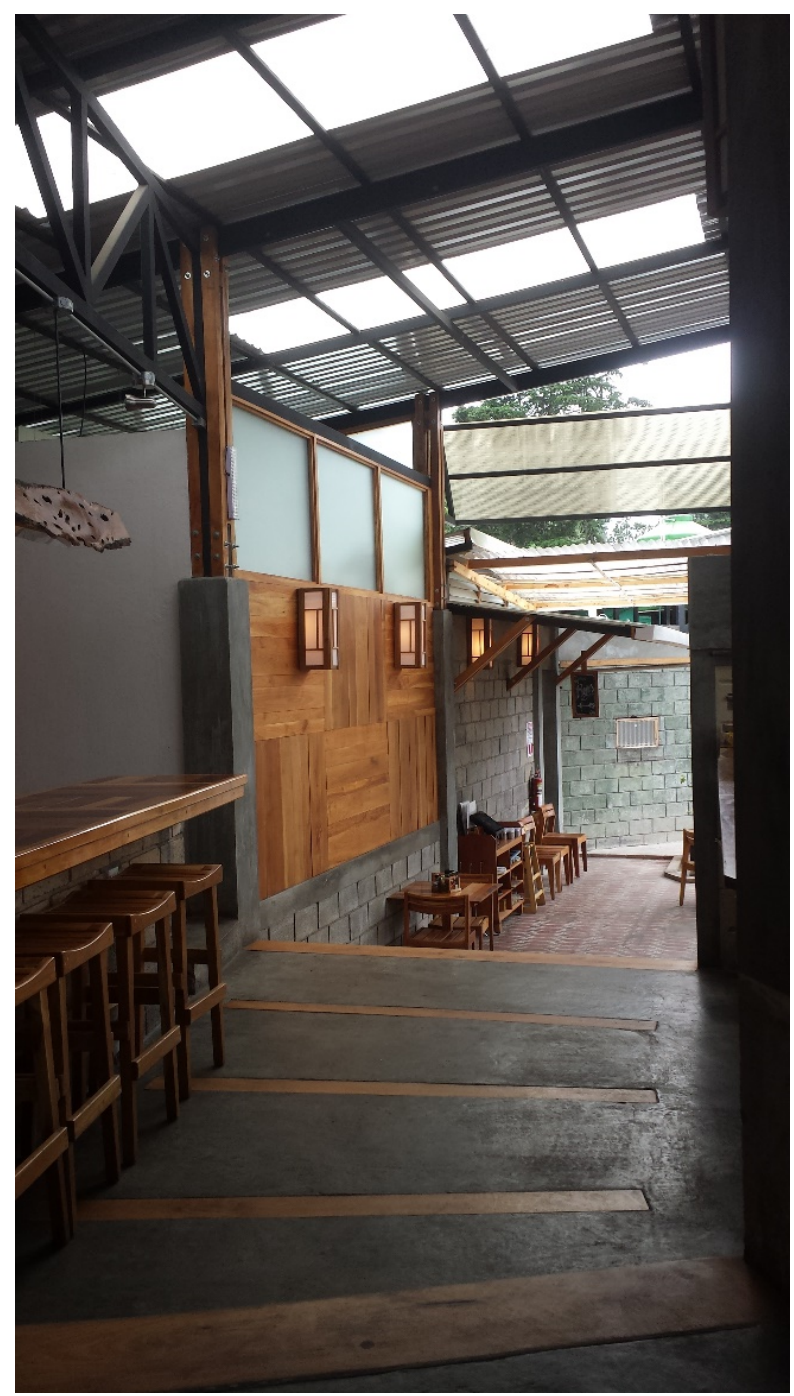

Fig. 2 Riverside Market, main vestibule.

Moreover, the vision pursued is being continuously enriched, matured and transformed over time, incorporating new input from friends, business partners, clients and the community.

\section{Making the Best out of the Existing}

The property is a 4,750 meter lot located 20 minutes outside of San Jose (capital of Costa Rica) on the highway to the Caribbean coast and Atlantic port on the outward-bound traffic side of the highway. It has approximately 50 meters of frontage on the main highway to the Caribbean. A stream runs along one of the sides and the back of the lot. The edge of the stream is wooded and the vegetation provides shade and a nice setting for outdoor seating, gardening, and other outdoor activities (Fig. 3).

The site was home to a Bar-Restaurant-Disco complex built back sometime in the 80's and burned down in the 90's. Before the project was built, the floors were burned out, and shell of these structures was all that remained on the site (Fig. 4). Under these conditions, it was decided that the construction footprint would not be enlarged with respect to the old existing remains. Further on, it was determined that the construction project would salvage as much as possible of the original structures and floors remaining in place. It was like building on top of the ruins of the "old paradigm" (Fig. 5).

Structural rehabilitation was implemented on as as-needed basis in order to save make most of the prior 


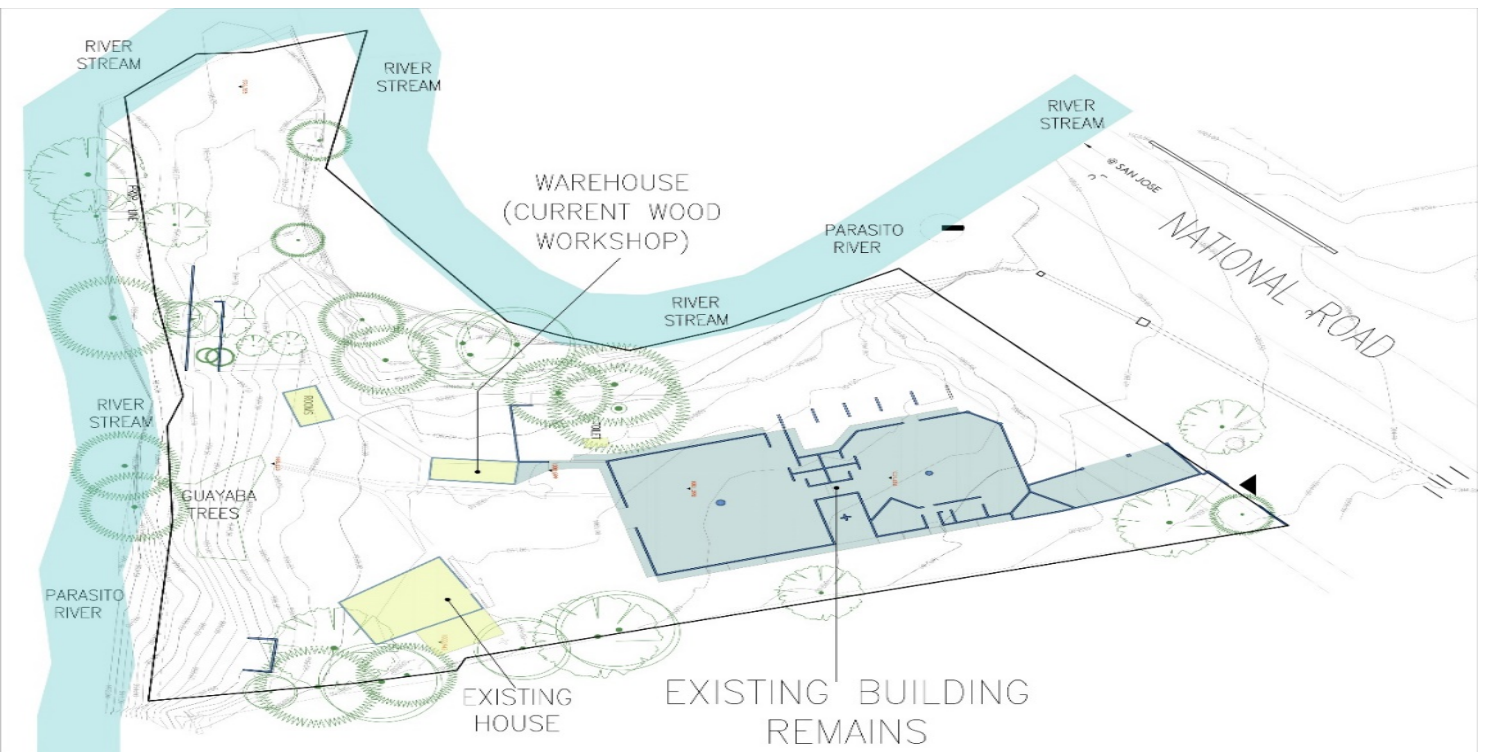

Fig. 3 Plan of existing physical conditions.

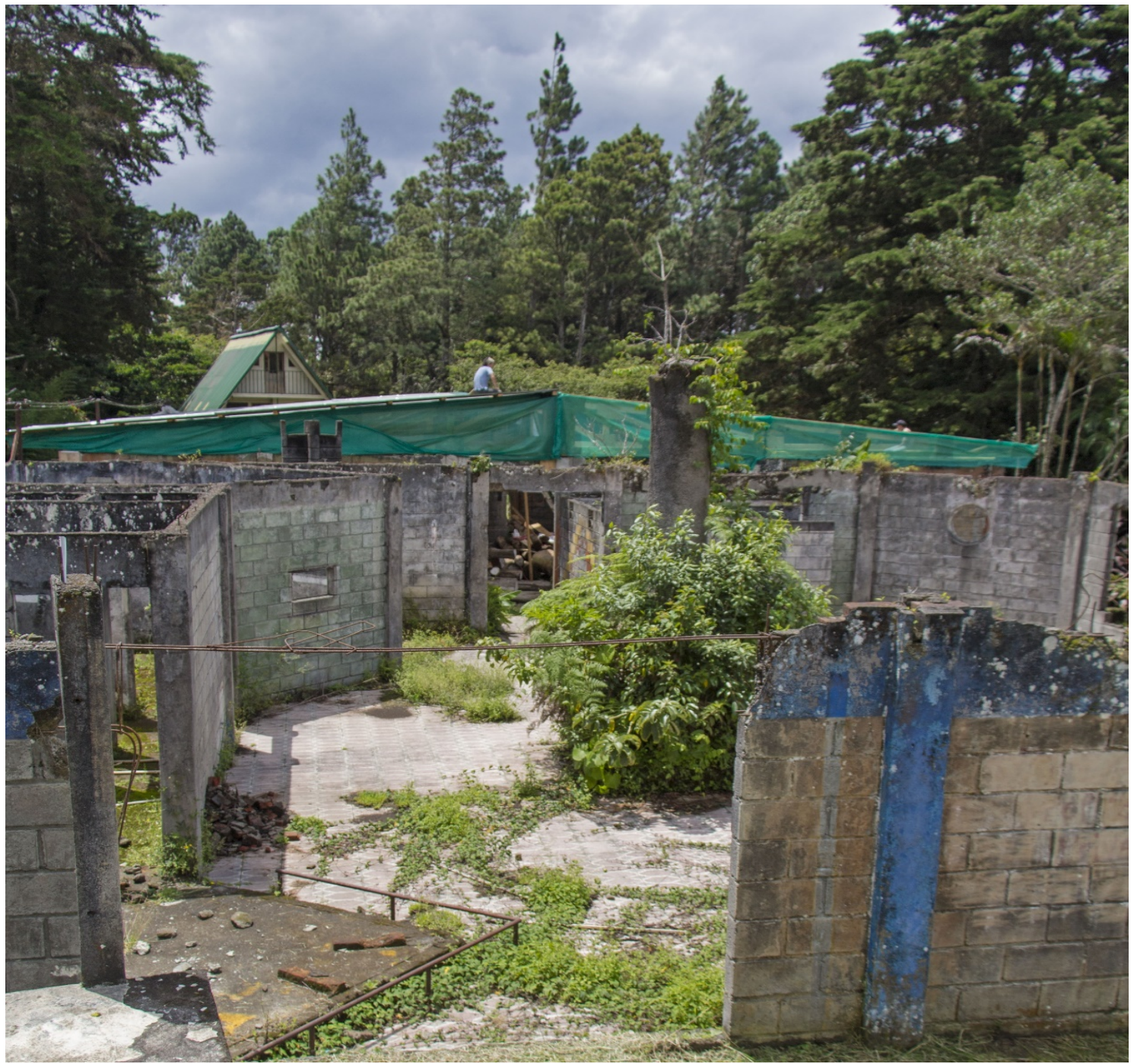

Fig. 4 Existing construction remains. 


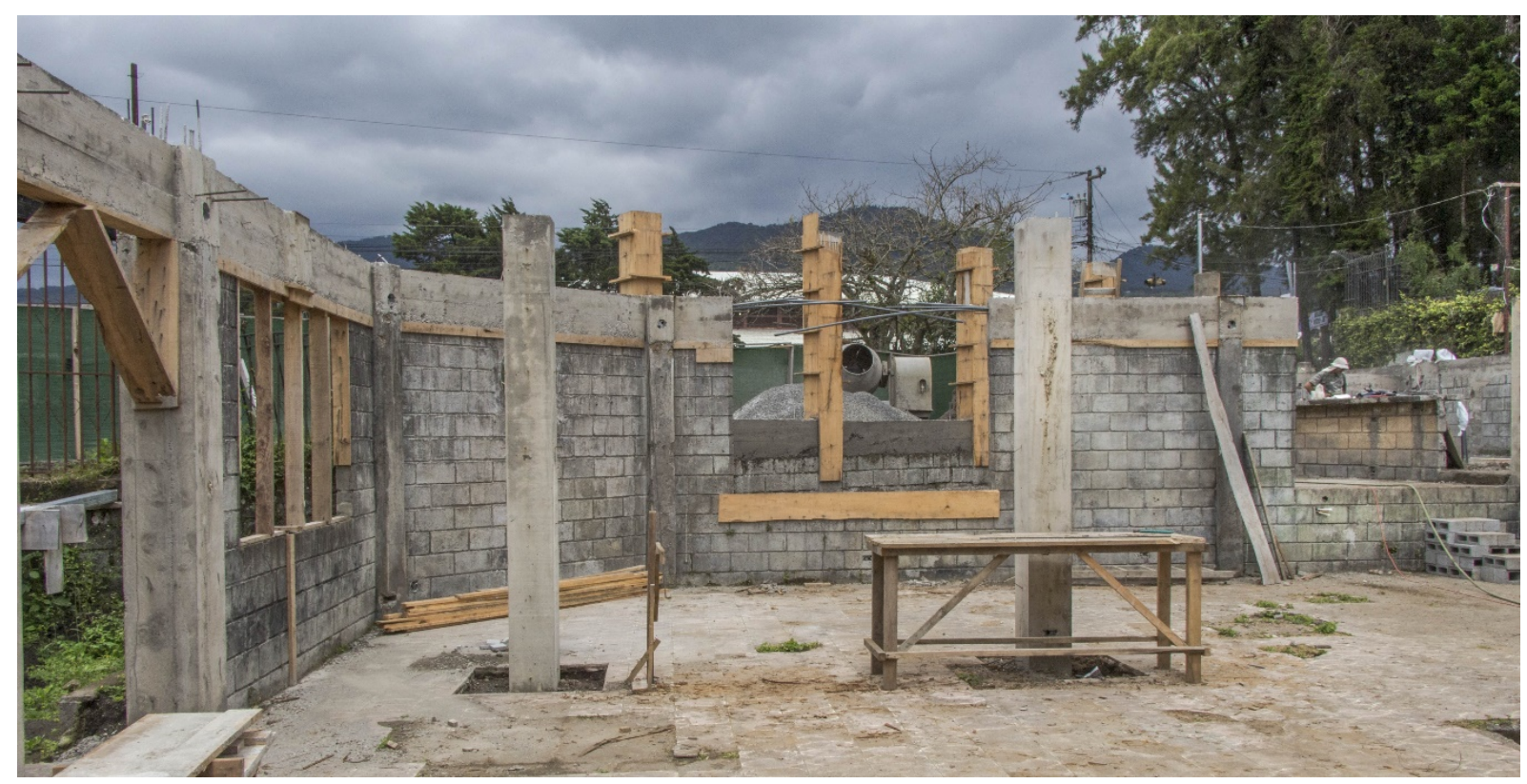

Fig. 5 Structural rehabilitation of existing damaged walls.

wall structures.

In addition to that, an existing A-frame house on the back side of the property was refurbished and made available for the budget eco-crowd. Since the startup, renters have been offered the opportunity to pay low price or even for the exchange of their work in the vegetable gardens. Meanwhile plans to improve the house over time are in place, increasing its rental capacity, while opening up the different living areas for greater ventilation, circulation and improved views. Future plans for it include a wrap-around porch, balconies, and dormers in order to improve building space use.

Finally, the back side of the existing main structure was taken over to install the wood processing shop to be used initially for construction purposes, but later for sustainable furniture production and on-site sales.

\section{On-site Wood w/o Orthodoxy}

Since Dan had reforestation wood available (cypress, teak and melina), not only from prior purchases and barter, but also from other nearby properties. It was given that the reconstructed structure in its new and improved form, was to be constructed in wood. Bearing that in mind, the original design was produced using the shapes and lengths that the on-site shop was able to produce. The result of this design proposal is shown in Fig. 6.

Nonetheless, just as construction started, it was clear that even while having an on-site wood processing shop, doing it all in wood would be a more expensive, difficult and slower process than having the benefit of freely introducing some light gauge steel elements which would significantly simplify the job. The simpler and actually cleaner result in terms of spaciousness and structural clarity is shown in Fig. 7 and Fig. 8. Roof height was planned bearing in mind vertical growth on second floor mezzanines, in order not to enlarge the existing building footprint over the course of future expansions.

\section{Passive, Local, Simple}

The simple building volume and tectonics were resolved both bearing in mind the respect of local vernacular practices and passive tropical principles. Form and tectonics followed the indications of weather and constraints, rather than a deciding upon a pre-determined style dictated from outside. In fact, some details were left to be resolved over time, knowing that "nature knows better" (Figs. 9 and 10). 


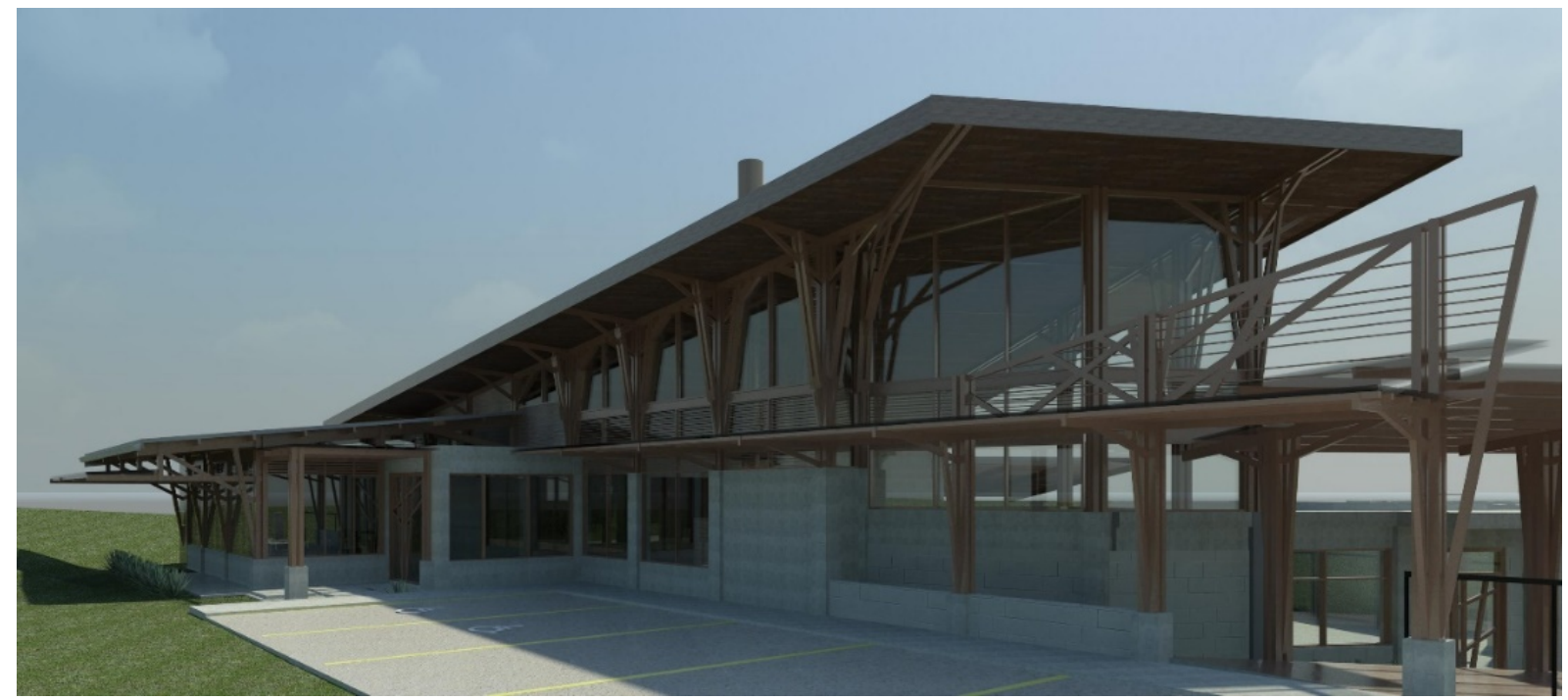

Fig. 6 Architectural/structural all-wood proposal.

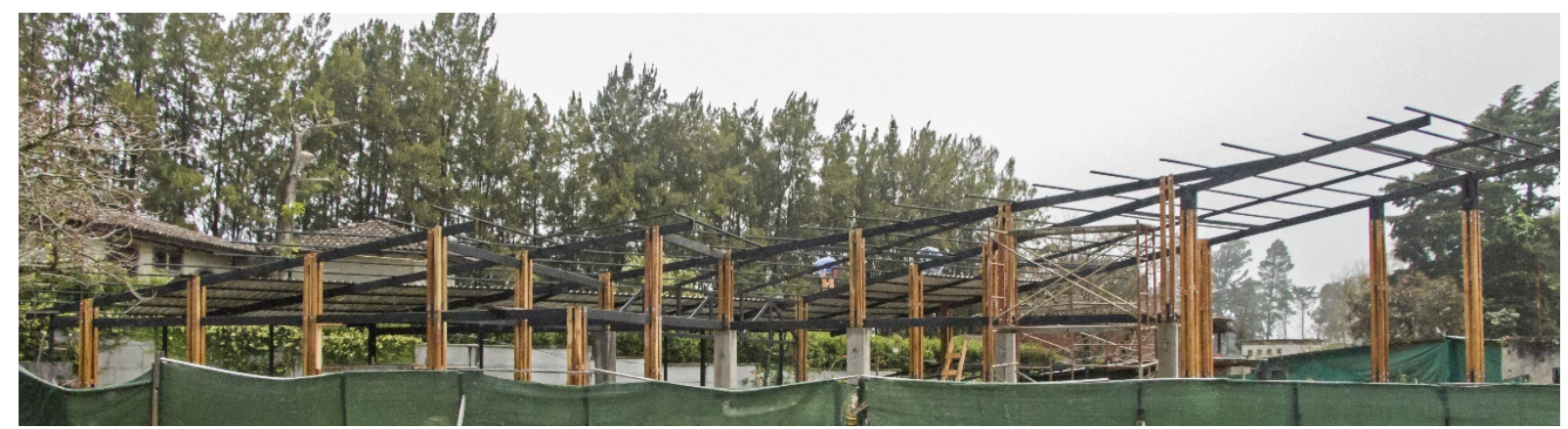

Fig. 7 Final structural resolution incorporating light gauge steel elements.

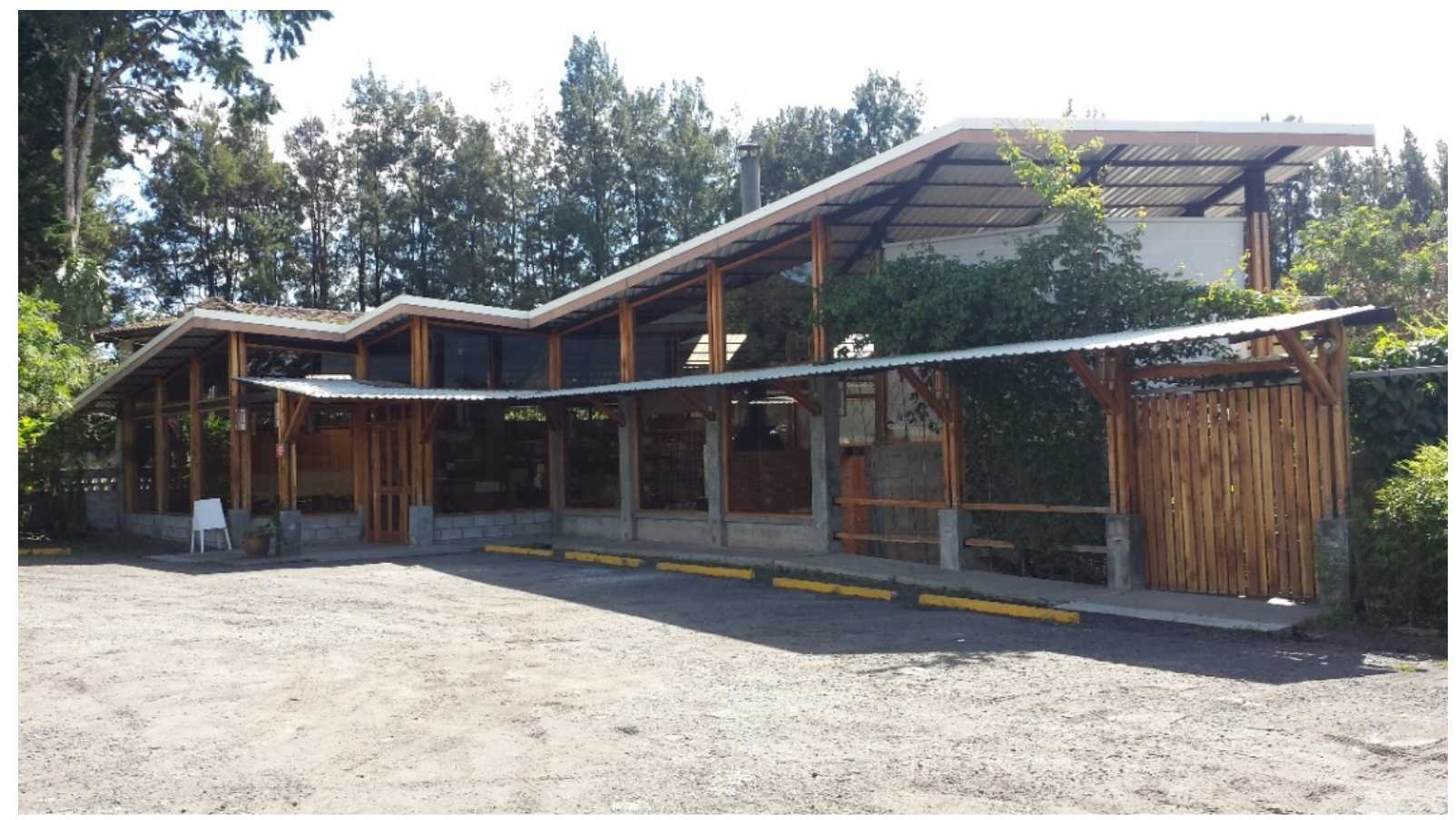

Fig. 8 Finished roadside café/restaurant. 


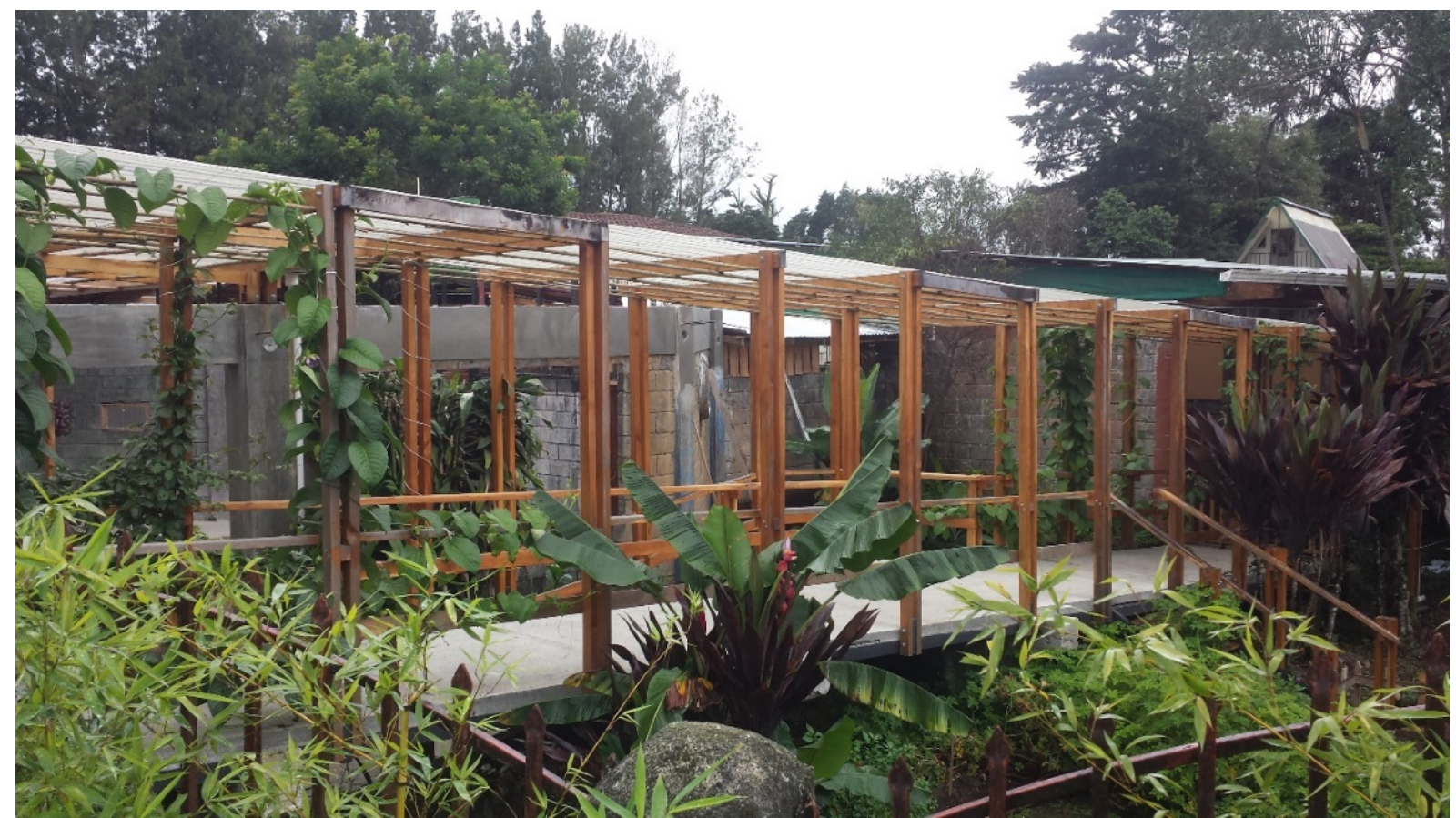

Fig. 9 Semi exposed and planted circulation pergola.

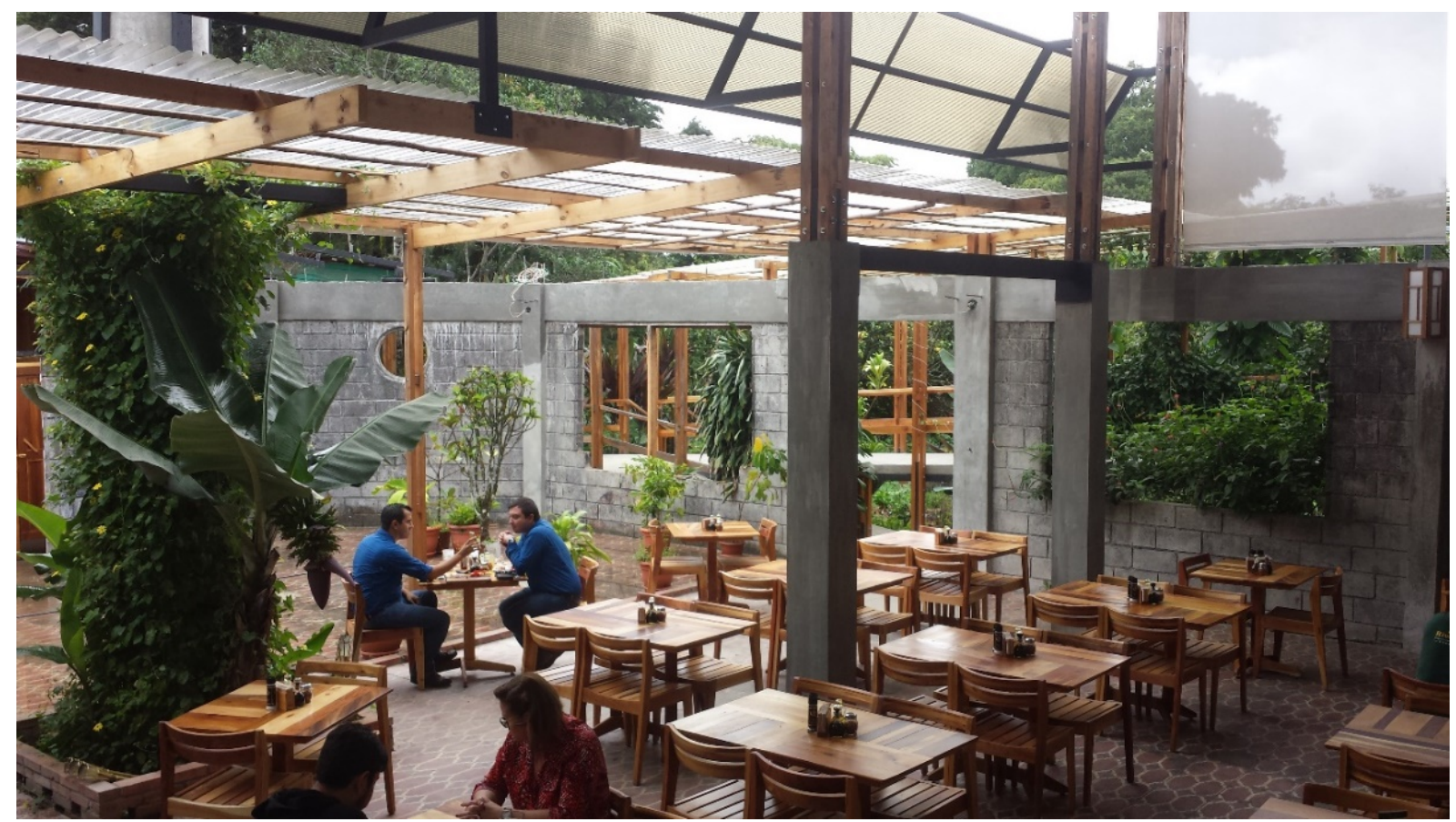

Fig. 10 Well shaded, ventilated space showing height and inside/outside alternations.

Among the main tropical passive features taken into consideration in the building design, we can cite the following $[7,8]$ :

- Use of tall, well ventilated roof structures with airy, indoor-outdoor feel, bearing in mind the alternation of hot/cool weather and rainy climate.
- Large overhangs and pergolas to deal with alternate sunny/rainy weather.

- Ceiling height alternations.

- Threading of inside/outside spaces, honoring and actualizing old-established vernacular practices.

As a result, the space created yields an open market 
feel with different informal seating options and potential spaces for future specialized kiosks and food stands. Further on, given its characteristics, the site offers outdoor seating options by the stream, under the trees among many other unpretentious, enjoyable interaction spaces that can be created over time (Fig. 11).

\section{Low Carbon Food}

The other key feature that inevitably both attracts and informs visitors on sustainable practice through lived experience is the low carbon food being produced in place. Of course this concept and practice is extrapolated to the rest of business options currently swarming around the place. Firstly, cooking has a very low energy consumption rate since most of the food served is cooked/baked in the brick oven built for this purpose (Fig. 14). Secondly, all of the organic food leftovers go to the on-site composting area that produces organic fertilizer for the on-site orchards.

In combination with the locally sourced organic produce and products utilized as part of the cooking and retail activities, this practice contributes to creating a truly sustainable project not only from its construction, but also from its operation and its complete life cycle standpoints. Thereby, the project sets an example on sustenance and adaptability to changing times and circumstances that demand the creation of low carbon cultural options within a contemporary framework begging for optimism (Fig. 12).

\section{Sustainable Building Model}

The other keystone of this discrete, yet successful project is the sustainable building model that it is set upon, first and foremost based upon the honoring of our local heritage, our traditional and locally produced foods and customs, yet incorporating some of the good and enjoyable influences that we inevitably receive from abroad in an era of cultural globalization. As said before, the business top priority is to buy from and use locally sourced produce (buy direct from farmers in the area), as well as use and promote innovative, locally produced goods and products.

In economic terms, the project has been self-financed, with some "bootstrapping" by the owner. This has demanded the ability to make small steps with small levels of investment over time in order to be able

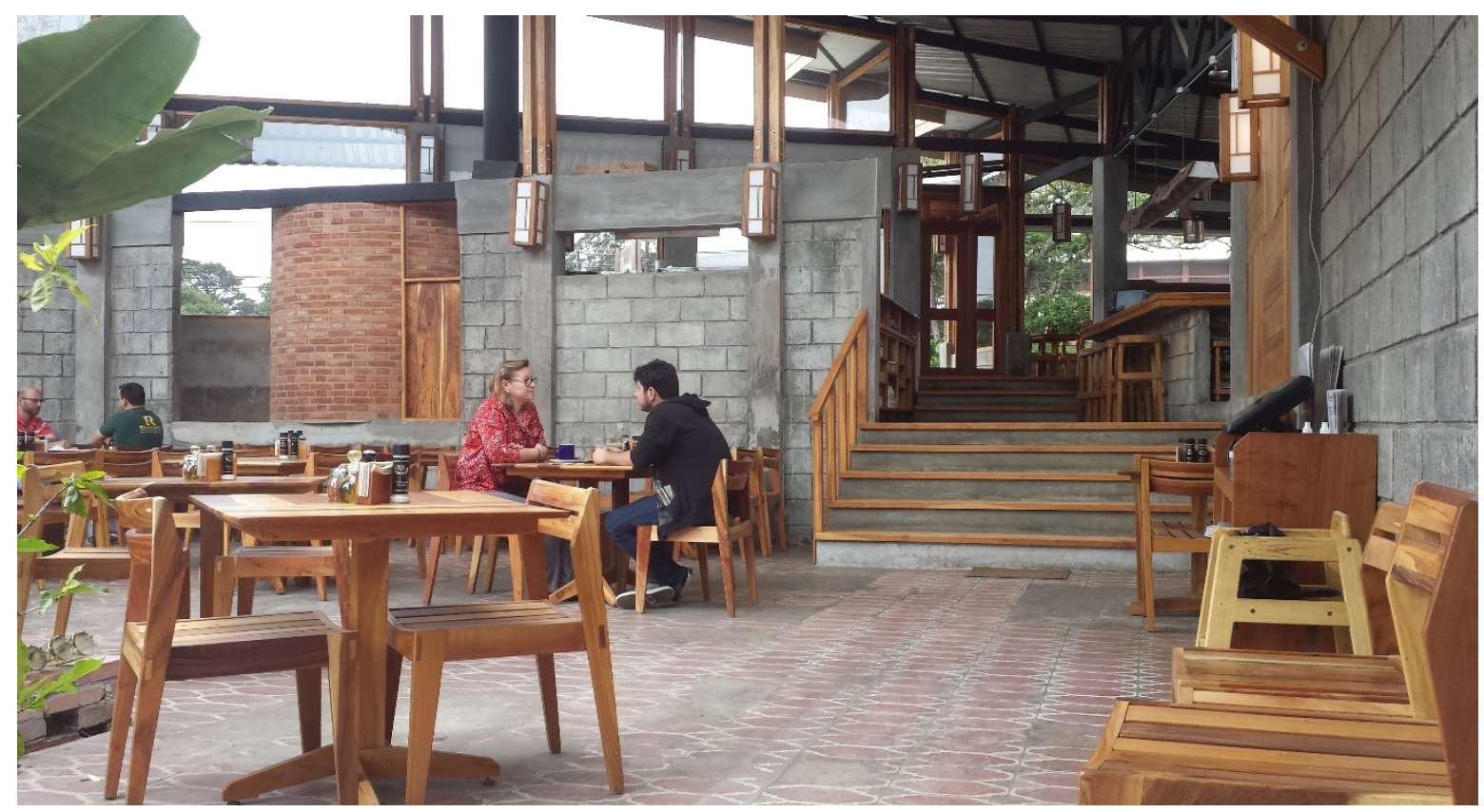

Fig. 11 Open, flexible space showing salvaged walls, wood structure, brick oven, on-site fabricated furniture. 


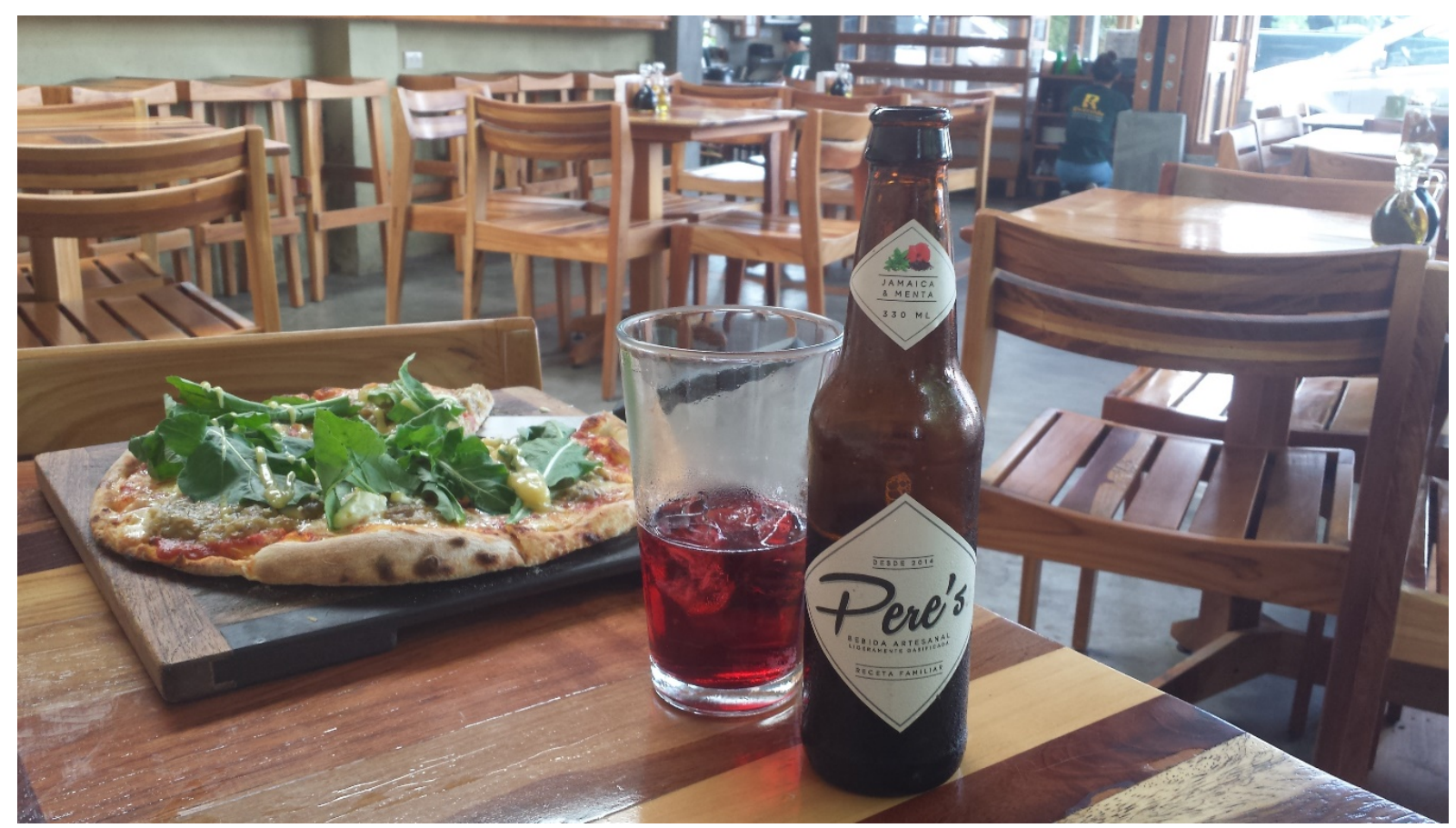

Fig. 12 Wood oven pizza with site-produced organic produce and artisan cold tea.

to achieve the project objectives.

The organization targets businesses with products and values that are compatible with the nature and values of the project. When warranted, the owner has been open to entertain different forms of alliances, partnerships, leases, build-to-suit agreements, and other configurations that will ultimately help attract and retain the ventures and people that are aligned and contribute/enrich/support the project values.

Ultimately, the goal of the owner is to create a self-sustaining conglomerate of micro-organizations, run by independent business managers, each with ownership, true expertise and passion for their business category (examples: baker, coffee roaster, chocolatier, organic produce trader, etc.). These businesses will ultimately either pay rent or share in their profits in order to provide ongoing cash-flow to the development. The owner is currently involved at the operational level in the overall marketplace and may choose to remain involved in some of the other upcoming business categories.
From its principles, the organization strives to make positive contribution to the local community, not only providing a space for healthy food, entertainment and information exchange, but also sourcing as much as possible from local farmers and businesses, thereby offering diverse opportunities for working and learning, careers and education, as well as opportunities for the development of local musicians, artists, self-motivated youngsters. Riverside Market currently promotes and performs training workshops on sustainable bio-agriculture, and participates in river cleanup/reforestation activities among other synergies, all within a triple bottom line approach.

\section{Outlook}

From the outset, it was decided that the project would start with a reduced number of small-scale initiatives in line with the overall project vision. Over time the project would evolve to fulfill its ultimate goals and vision through an adaptive and organic growth process that would allow to incorporate the learnings along the 
path back into the design/construction/operation. Thereby, the resulting living project would be an adaptive system under demand-driven growth.

From the initially small roadside café once envisioned, which would act as a small-scale example and concept for rest of the project, in combination with a small backpackers lodge on the back, the owner is currently in conversations to introduce a permanent organic produce market, a second brick oven bakery space, a space dedicated to coffee roasting and gourmet

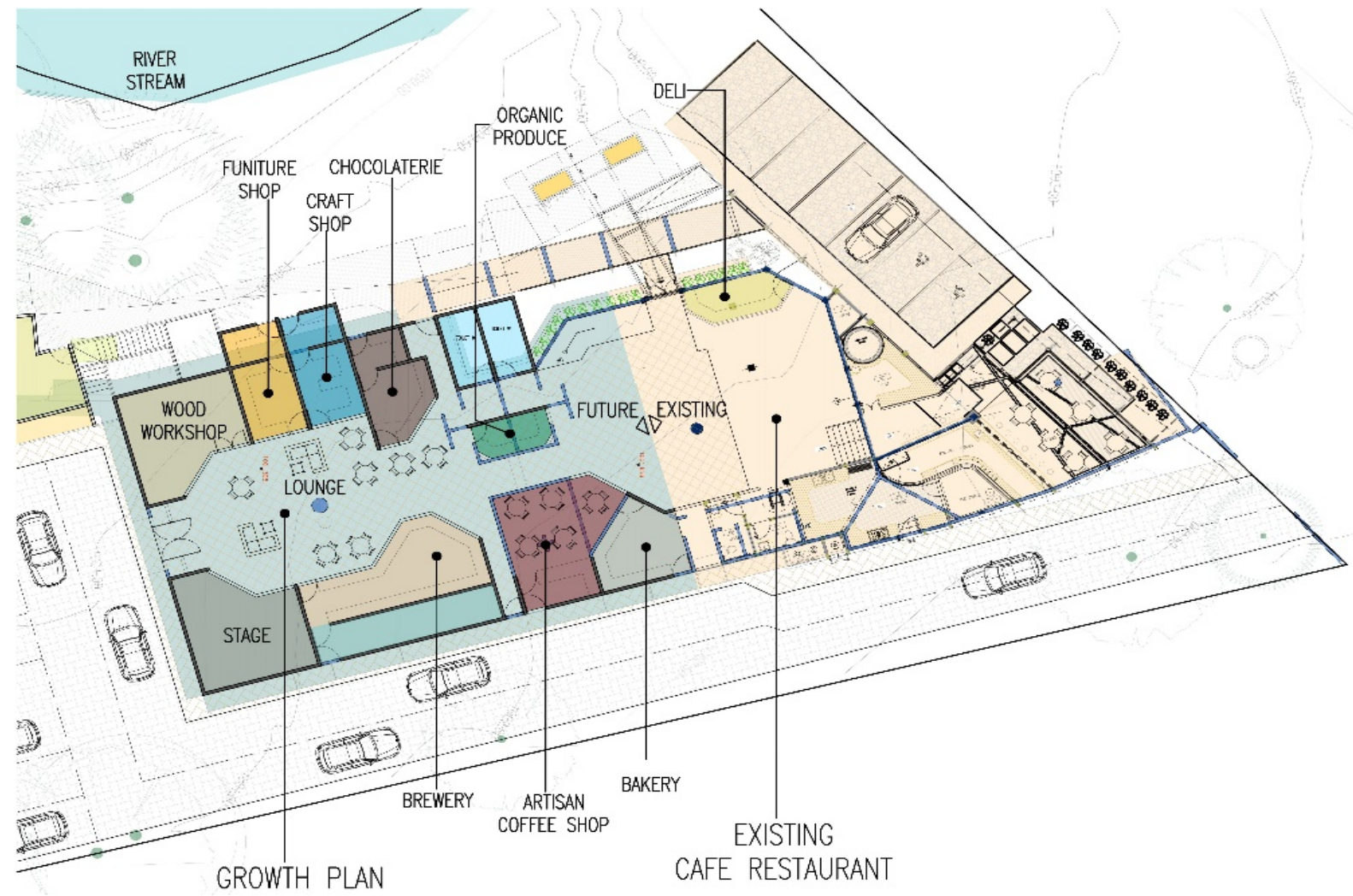

Fig. 13 Current Riverside Market master growth plan.

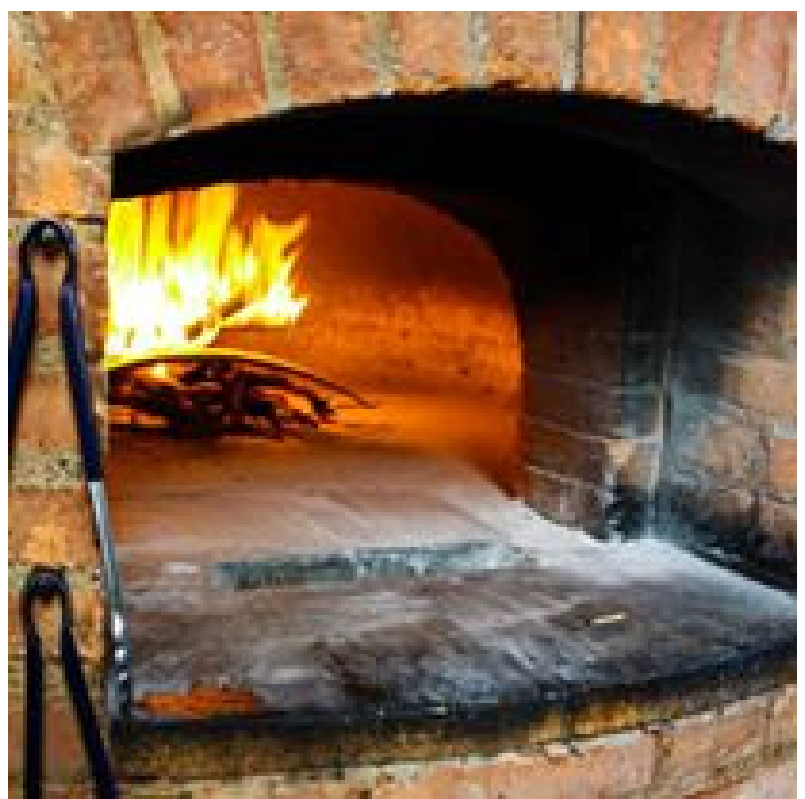

Fig. 14 Core of the brick oven. 
organic coffees, another space for the production and sales of Costa Rican organic chocolate, among other that are part of the updated master growth plan developed by the authors (Fig. 13).

\section{Conclusion}

Riverside Market in San Isidro de Heredia, Costa Rica is a small but meaningful and locally successful project in terms of sustainable building practice, business model and operations, social and cultural influence, as well as a contemporary business organization based on principles of sustenance and adaptability. The key of the positive results obtained is the dedicated implementation of the vision and values established up front, while making the best out of the existing physical possibilities at hand, employing technically proven practices without falling upon orthodoxy, working at the service of a truly low carbon approach and establishing a sound and sustainable business model. Improvements are possible and desirable, especially regarding more technical rigor, data gathering and processing/monitoring.

\section{References}

[1] Gunderson, L., Allen, C., and Holling, C., eds. 2009. Foundations of Ecological Resilience. Washington, DC: Island Press.

[2] Holmgren, D. 2002. Permaculture-Principles and Pathways beyond Sustainability. Victoria, Australia: Holmgren Design Services.

[3] Homer Dixon, T. 2006. The Upside of Down-Catastrophe, Creativity and the Renewal of Civilization. Washington, DC: Island Press.

[4] Illich, I. 1973. La Convivialité. Paris: Editions du Seuil.

[5] Nicolescu, B., ed. 2008. Transdisciplinarity - Theory and Practice. NJ, USA: Hampton Press Inc.

[6] Odum, H. T., and Odum, E. 2001. A Prosperous Way Down-Principles and Policies. Boulder: University Press of Colorado.

[7] Liébard, A., and De Herde, A. 2000. Guide de l'architecture bioclimatique-Tome 2: Construire avec le climat. Paris, France: Observatoire des énergies renouvelables.

[8] Sacré, C., Millet, J. R., Gandemer, J., and Barnaud, G. 1992. Guide sur la climatisation naturelle de l'habitat en climat tropical humide. Tome 1: Méthodologie de prise en compte des paramètres climatiques dans l'habitat et conseils pratiques. Nantes, France: Centre Scientifique et Technique du Bâtiment. 